\title{
Frequency of Anxiety and Depression in Migraine - A study of 102 Patients
}

\author{
M. Munir Hamirani, Sohail Ahmed and Mohan Lal Luhano
}

\begin{abstract}
OBJECTIVE: The study was aimed to see the frequency of Anxiety and Depression among patients with Migraine.

DESIGN: Cross sectional study.

SETTING: Department of Psychiatry, Abbasi Shaheed Hospital Karachi and Department of Psychiatry Ziauddin University Hospital, KDLB campus, Kemari Karachi

DURATION: ${ }^{\text {st }}$ June 2007 to $30^{\text {th }}$ November 2007

METHODS: Referred patients of headache diagnosed as suffering from migraine were selected for the study. Diagnosis of migraine was based on the criteria for migraine designed by International Headache Society. Patients were enrolled irrespective of age and sex. Only those patients were included who fulfilled the selection criteria. Any routine or relevant investigations wherever required were carried out. Following selection of the cases, the patients were administered the Hospital Anxiety \& Depression Scale, Urdu version. All the findings were recorded on a preformed Proforma. The data were compiled, tabulated and analyzed using SPSS version 10.

RESULTS: One hundred and two patients with migraine comprising 65 females (63.8\%) and 37 males (36.2\%), minimum age of presentation 11 years and maximum 71 years completed the study. Majority of the patients (75\%) aged between 20 and 50 years. On screening for psychiatric caseness using the validated Urdu Version of Hospital Anxiety and Depression Scale with a cutoff score of $11-21$ for both anxiety and depression 58 patients (56.8\%) had psychiatric morbidity. Therefore, 44 patients (43.1\%) were not positive for psychiatric caseness. Of the 58 patients with positive psychiatric caseness, there were 23 males $40 \%$ ) and 35 females (60\%). These included 25 patients (43\%) with anxiety, 18 patients (31\%) of depression while 15 patients (26\%) had both anxiety and depression. Eighty percent of the 58 patients with positive psychiatric caseness aged between $20-50$ years.

CONCLUSION: Migraine has a significant association with anxiety and depression. Frequency of this association may be influenced by sex and age.
\end{abstract}

KEY WORDS: Migraine, Anxiety, Depression, HADS.

\section{INTRODUCTION}

Migraine is an episodic disorder, characterized by attacks of headache and associated symptoms. It is a common, chronic neurological disorder that affects $12 \%$ or more of the adult population in Western countries ${ }^{1}$. It is a heterogeneous condition that results in a spectrum of disability within and among different subjects ${ }^{2}$. The disability of migraine can be severe and a considerable burden to the sufferer and to society. Despite significant disability, migraine is an underrecognized, under-diagnosed and under-treated condition ${ }^{2}$. Migraine results from altered neurochemical, electrical and vascular changes in the nervous system. ${ }^{3,4}$ Anxiety and depression are common among people with migraine and remain largely unrecognized $^{5}$. Association between migraine and a variety of psychiatric and somatic conditions has been reported in the literature. Migraine has been reported in all age groups but most commonly between 25-55 years of age ${ }^{6}$. It has been found commonly in all ethnic groups. ${ }^{7}$ An association between migraine, depression and anxiety has been consistently reported. A high prevalence of anxiety (70\%) and depression $(52 \%)$ in female migraine sufferers has been reported ${ }^{8}$. A high prevalence of depression is also reported by Shehbaz $\mathrm{N}$ et al ${ }^{9}$ in their study of migraine patients in an outpatient setting. Most of the population-based studies have demonstrated an association between major depression and migraine ${ }^{10-14}$. They may represent a direct or indirect etiologic effect of one condition on the other, an effect of one condition on the prognosis or mortality associated with the other, or an impact of shared environmental or genetic risk factors. Various studies have been conducted worldwide to determine the frequency of anxiety and depression in patients with migraine. Different scales can be util- 
ized for the purpose but the results of one study may not be comparable to others. This in turn depends upon the study design and the setting. In the current study, we have employed HADS ${ }^{15}$ (Hospital Anxiety and Depression Scale) Urdu version ${ }^{16}$. Urdu version of HADS has also been used in other studies, done locally ${ }^{9}$. This standardized scale facilitates the screening for psychiatric problems in our locality. ${ }^{17}$ Current study was targeted to determine the frequency of anxiety and depression among diagnosed patients of migraine in local setting.

\section{MATERIAL \& METHODS}

The cross sectional study was carried out at the department of Psychiatry, Abbasi Shaheed Hospital \& department of Psychiatry, Ziauddin university hospital. Patients referred from the medical Out Patient Departments with complaint of headache from $1^{\text {st }}$ June 2007 to $30^{\text {th }}$ November 2007 were considered for the study. Referred patients of headache were interviewed after an informed consent and their demographic details were recorded on a specific proforma designed for this purpose. A detailed history and examination was carried out. Diagnosis of migraine was based on the criteria for migraine designed by International Headache Society. Required routine \& relevant investigations were done when ever required. Patients were enrolled irrespective of age and sex. Patients suffering from any other medical or surgical problem were not included in the study. Patients receiving any anxiolytics or antidepressants were also ruled out. Only those patients of migraine were selected who could complete the Urdu Proforma by themselves. Following selection of cases, the patients were administered Hospital Anxiety \& Depression scale, Urdu version. Based on Snaith and Zigmond's interpretation of HADS score ${ }^{18}$, a cut off value of 11-21 was used to identify both anxiety and depression. All the findings were recorded on a preformed Proforma. The data were compiled tabulated and analyzed using SPSS version 10.

\section{RESULTS}

A total of 102 patients with migraine completed the study comprising 65 females (63.8\%) and 37 males (36.2\%). Minimum age of presentation was 11 years and maximum of 71 years while mean age of presentation was $37.1 \pm 8.84$ years. Table 1 reveals the age wise breakup of these patients. Maximum number (34) of patients (33.3\%) was aged between 40 and 49 years. It can further be appreciated that majority of the patients (75\%) aged between 20 and 50 years (Table I). Upon screening for psychiatric caseness using validated Urdu version of Hospital Anxiety and Depres- sion Scale with a cutoff value of $11-21$ for both anxiety and depression, 58 patients $(56.8 \%)$ had psychiatric morbidity. Remaining, 44 patients (43.1\%) were not having psychiatric problem. Of the 58 patients with positive psychiatric assessments, there were 23 males (40\%) and 35 females (60\%) (Table II). These included 25 patients $(43 \%)$ with anxiety, 18 patients (31\%) of depression while15 patients (26\%) had both anxiety and depression. Out of 37 male patients of migraine 23(62.16\%) had psychiatric co-morbidity while out of 65 female patients of migraine 35 (53.85\%) had psychiatric co-morbidity. Among patients of migraine who had anxiety alone females constituted $60 \%(15 / 25)$ while $40 \%$ were males (10/25). Of the patients with depression there were 12/18 females (66.6\%), while 6/18 males constituted 33.3\%. Of the patients with both anxiety \& depression there were $7 / 15$ males $(46.6 \%)$ while $8 / 15$ were females (53.3\%) (Table III). Age wise distribution of those patients of migraine with positive psychiatric caseness is given in Table IV. It can be appreciated that $80 \%(58)$ of the patients with positive psychiatric caseness aged between 20-50 years.

TABLE I: AGE DISTRIBUTION $(n=102)$

\begin{tabular}{|l|l|c|}
\hline \multicolumn{1}{|c|}{ Age } & $\mathbf{n}$ & \% \\
\hline $10-19$ yrs & 11 & 10.8 \\
\hline $20-29$ yrs & 22 & 21.6 \\
\hline $30-39$ yrs & 19 & 18.6 \\
\hline $40-49$ yrs & 34 & 33.3 \\
\hline $50-59$ yrs & 11 & 10.8 \\
\hline $60-69$ yrs & 04 & 3.9 \\
\hline$>70$ yrs & 01 & 0.9 \\
\hline Total & & $\mathbf{1 0 2}$ \\
\hline
\end{tabular}

TABLE II: SEX DISTRIBUTION OF PATIENTS $(n=102)$

\begin{tabular}{|l|c|c|c|}
\hline $\begin{array}{c}\text { Male } \\
\text { Female } \\
\text { Distribu- } \\
\text { tion }\end{array}$ & $\begin{array}{c}\text { Patients } \\
\text { with psy- } \\
\text { chiatric } \\
\text { morbidity }\end{array}$ & $\begin{array}{c}\text { Patients } \\
\text { without } \\
\text { psychiatric } \\
\text { morbidity }\end{array}$ & $\begin{array}{c}\text { Total num- } \\
\text { ber of pa- } \\
\text { tients }\end{array}$ \\
\hline Males & $23(62.1 \%)$ & $14(37.8 \%)$ & 37 \\
\hline Females & $35(53.8 \%)$ & $30(46.1 \%)$ & 65 \\
\hline Total & $\mathbf{5 8 ( 5 6 . 8 \% )}$ & $\mathbf{4 4 ( 4 3 . 1 \% )}$ & 102 \\
\hline
\end{tabular}


TABLE III:

SEX DISTRIBUTION AND PSYCHIATRIC MORBIDITY IN PATIENTS OF MIGRAINE $(n=102)$

\begin{tabular}{|l|c|c|c|c|c|}
\hline $\begin{array}{c}\text { Sex Wise } \\
\text { Distribution }\end{array}$ & $\begin{array}{c}\text { Patients of } \\
\text { migraine with } \\
\text { Anxiety alone }\end{array}$ & $\begin{array}{c}\text { Patients of Mi- } \\
\text { graine with De- } \\
\text { pression alone }\end{array}$ & $\begin{array}{c}\text { Patients of Migraine } \\
\text { with both Anxiety \& } \\
\text { Depression }\end{array}$ & $\begin{array}{c}\text { Patients of Migraine } \\
\text { without Anxiety or } \\
\text { Depression }\end{array}$ & $\begin{array}{c}\text { Total number } \\
\text { of patients }\end{array}$ \\
\hline Females & 15 & 12 & 8 & 30 & 65 \\
\hline Males & 10 & 6 & 7 & 14 & 37 \\
\hline
\end{tabular}

TABLE IV:

AGE DISTRIBUTION PATIENTS WITH POSITIVE PSYCHIATRIC CASENESS $(n=58)$

\begin{tabular}{|l|c|c|}
\hline \multicolumn{1}{|c|}{ Age } & $\mathbf{n}$ & \% \\
\hline 10-19 yrs & 3 & 5.2 \\
\hline $20-29 \mathrm{yrs}$ & 13 & 22.4 \\
\hline $30-39 \mathrm{yrs}$ & 11 & 19.0 \\
\hline $40-49 \mathrm{yrs}$ & 22 & 38.0 \\
\hline $50-59 \mathrm{yrs}$ & 2 & 10.3 \\
\hline $60-69 \mathrm{yrs}$ & 6 & 3.4 \\
\hline$>70 \mathrm{yrs}$ & 01 & 1.7 \\
\hline Total & $\mathbf{5 8}$ & $\mathbf{1 0 0}$ \\
\hline
\end{tabular}

\section{DISCUSSION}

The clinical manifestations of migraine are variable, across a broad spectrum of presentations. Migraine results from altered neurochemical, electrical and vascular changes in the nervous system. ${ }^{3,4}$ Anxiety and depression are common among people with migraine and remain largely unrecognized. ${ }^{5}$ Association between migraine and a variety of psychiatric and somatic conditions has been reported in the literature. Various studies have been conducted worldwide to determine the frequency of anxiety and depression in patients with migraine. ${ }^{10-14}$ In the current study, we have employed HADS (Hospital Anxiety and Depression Scale) Urdu version. The use of HADS as a screening instrument in local psychiatric setting has been validated. ${ }^{17} \mathrm{~A}$ total of 102 patients with migraine completed the study comprising 65 females $(63.8 \%)$ and 37 males (36.2\%). Fifty eight patients $(56.8 \%)$ of the enrolled cases had psychiatric morbidity. Therefore, 44 patients (43.1\%) were not positive on evaluation for psychiatric illness. Of the 58 patients with positive psychiatric caseness, there were 23 males $(40 \%)$ and 35 females (60\%). Psychiatric co-morbidity was present in $62.14 \%$ among male subjects while it was present in $53.85 \%$ among female subjects. Thus the frequency of psychiatric caseness was higher in males as compared to others. Other workers have reported the frequency to be higher in females. ${ }^{8}$ However; the results can vary from one study to another depending upon the clinical setting, study design, sample size and the population studied. Another study by Stewart et $\mathrm{al}^{19}$ reports the frequency of psychiatric morbidity in the form of panic disorder to be quite higher in males as compared to female sufferers of migraine. Thus increased frequency of psychiatric morbidity in males in the above mentioned study supports the results of our study. Therefore, any sex preponderance may be of unknown significance. Majority of our patients with migraine (75\%) were in between $20-50$ years of age. Migraine has already been reported to be most common in the age between 25-50 years. ${ }^{6}$ Almost $80 \%$ patients in this study with anxiety and depression were aged 20-50 years. This data in turn seems to be on almost near to past studies. ${ }^{6}$ It can readily be appreciated from the results that anxiety and depression have a significant association with migraine. Frequency of anxiety and depression in our study was $56 \%$. These included 25 patients (43\%) with anxiety, 18 patients $(31 \%)$ of depression while15 patients $(26 \%)$ had both anxiety and depression. Workers world wide have reported the association consistently. ${ }^{20-21}$ Breslau et al, ${ }^{22}$ also found that, migraine sufferers are more likely to have affective disorders like major depression. Shehbaz $\mathrm{N}$ et al, ${ }^{9}$ also reported a high frequency of depression in migraine sufferers as $40 \%$ of their migraine patients were found to have depression in their study. Thus affective disorders are frequently found as co morbidity in patients of migraine. The situation is likely to be similar in this part of the world, as reflected by the results of our study. Mc Williams et $\mathrm{al}^{23}$ have reported higher frequency of anxiety in patients with migraine as compared to controls. Devlen et al, ${ }^{5}$ have reported even a higher frequency of anxiety and depression in his patients. In another study, ParejaAngel ${ }^{8}$ et al, also found a high prevalence of anxiety and depression in their study with frequency of $70 \%$ and $50 \%$ respectively. In another study, the prevalence of major depression was elevated in all migraine groups compared to controls on both crude and adjusted (by age, sex, education) prevalence ratios. ${ }^{24}$ For this consistent association Merkingas et $\mathrm{al}^{20}$ have 
suggested migraine with anxiety and depression to be a distinct syndrome comprising anxiety, manifesting in early childhood, followed by migraine headaches, and then by discrete episodes of depressive disorder in adulthood. Thus the findings in our study are consistent with the reports in literature. As the results in our study are comparable to those found in international literature, there is a need to evaluate all migraine patients for psychiatric morbidity also. The presence of migraine increases a patient's risk of developing depression, whereas the presence of depression is associated with a greater risk of developing migraine, but not non-migraine headache. ${ }^{25}$ Depression may potentially be under-diagnosed in migraine sufferers because it may present differently than it does in persons without migraine. Clinicians may fail to inquire about or may minimize depressive symptoms because they may consider them to be normal adaptations to the pain associated with migraine. The clinical and public health implications of our results are threefold. . First, clinicians should have a high index of suspicion for depression and anxiety in migraine patients. Second, services for people with migraines should plan for access to psychiatric consultation and expertise. Third, as migraine has a substantial impact on population mental health, there may be a role for public health interventions like public education or screening programs targeting the general population. There are certain limitations of our study. First, the effect of other variables (like age, duration of illness and associated stressors) on the development of psychiatric morbidity has not been studied. Secondly the study was conducted on a relatively small sample population. It would be interesting to conduct similar studies on larger groups of the local population.

\section{CONCLUSION}

It can be concluded from the study that migraine has a significant association with anxiety and depression. Frequency of this association may be influenced by sex and age. There is a need for studies to be conducted on larger sample sizes in this regard. Frequent headache can lead to depression, anxiety and impaired quality of life. Therefore such patients should be evaluated for the presence of psychological disturbance.

\section{REFERENCES}

1. Scher Al, Stewart WF, Lipton RB. Migraine and headache: a meta-analytic approach. IASP press 1999;159-70.

2. Stewart WF, Shechter A, Lipton RB. Migraine heterogeneity. Disability, pain intensity, and attack frequency and duration. Neurology 1994;4(6):2439.
3. Goadsby PJ, Pathophysiology of headache In: Wolff's Headache and Other Head Pain, 7th ed., (Silberstein SD, Lipton RB, Dalessio DJ, eds) New York; Oxford University Press, 2001: pp57-72.

4. Moskowitz MA, Basic mechanisms in vascular headache. Neurol Clin 1990 : 8(4):801-15.

5. J Devlen. Journal of the Royal Society of Medicine, Vol 87, Issue 6 338-341, Copyright (c) 1994 by Royal Society of Medicine Department of General Practice, University of Manchester, UK

6. Lipton RB, Stewart WF. Prevalence and impact of migraine. Neurology Clinics 1997:15(1):1-13.

7. Headache classification committee of the IHS. Classification and diagnostic criteria for headache disorders, cranial neuralgias and facial pain. Cephalalgia 1988 8: 1-96.

8. Pareja-Angel J, Campo-Arias. A The prevalence of symptoms of anxiety and depression in female migraine sufferers Rev Neurol. 2004;39(8):711-4.

9. Shehbaz N, Ali S, Akhtar W, Aziz H. Migraine: comorbidity with depression Pak J Med Sci Mar 2007; 23(1):95-9.

10. Davis GC, Andreski P. Migraine, psychiatric disorders, and suicide attempts: an epidemiologic study of young adults. Psychiatry Res 1991; 37 (1):11-23.

11. Fasmer OB. The prevalence of migraine in patients with bipolar and unipolaraffective disorders. Cephalalgia 2001;21:894-9.

12. Silberstein SD. Shared mechanisms and comorbidities in neurologic and psychiatric disorders. Headache 2001;41(Suppl 1):S11-S17.

13. Swartz KL, Pratt LA, Armenian HK, Lee LC, Eaton WW. Mental disorders and the incidence of migraine headaches in a community sample: results from the Baltimore Epidemiologic Catchment area follow-up study. Arch Gen Psychiatry 2000;57:945-50.

14. Breslau N. Psychiatric comorbidity in migraine. Cephalalgia 1998 ;18 (Suppl22):56-8.

15. Zigmond AS, Snaith RP. The Hospital Anxiety and Depression Scale. Acta Psychiatr Scand 1983; 67: 361-70.

16. Mumford DB, Tareen IAK, Bajwa MAZ, Bhatti $M R$, Karim R. The translation and evaluation of an Urdu version of the Hospital Anxiety and Depression Scale . Acta Psychiatrica Scandinavica 2007; 83(2):81-5.

17. Karim R, Abdul Shakoor, Tareen IAK. The Hospital Anxiety and Depression Scale AAA: A Simple and Rapid Instrument for evaluation of Depression in Psychiatric Settings Ann of King Edward Med Coll 1998; 4(2):29 -31.

18. Snaith RP, Zigmond AS. The Hospital Anxiety and Depression Scale Manual. NFER: Nelson, Win- 
dsor; 1994

19. Stewart WF, Linet MS, Celentano DD. Migraine headaches and panic attacks. Psychosom Med 1989; 51(5):559-69.

20. Merikangas $\mathrm{KR}$, Angst $\mathrm{J}$, Isler $\mathrm{H}$. Migraine and psychopathology: Results of the Zurich Cohort Study of Young Adults. Arch Gen Psychiatry 1990;47:849-53.

21. Breslau N, Davis GC. Migraine, physical health and psychiatric disorder: a prospective epidemiologic study in young adults. J Psychiatr Res 1993; 27(2):211-21.
22. Breslau N, Schultz LR, Stewart WF. Headache and major depression: is the association specific to migraine? Neurology $2000: 54(2): 308-13$.

23. McWilliams LA, Goodwin RD, Cox BJ. Depression and anxiety associated with three pain conditions: Results from a nationally representative sample. Pain 2004;111:77-83.

24. Patel N, Bigal ME, Kolodner K. (in press), The prevalence of migraine and probable migraine in a health plan. Neurology.

25. Migraine, depression, and "internal" environmentalism. Headache 2002;42:843-4.

AUTHOR AFFILIATION:

Dr. M. Munir Hamirani (Corresponding Author)

Associate Professor of Psychiatry

Abbasi Shaheed Hospital \& Karachi Medical \& Dental College

Karachi, Sindh-Pakistan.

Email: mmham@cyber.net.pk

Dr. Sohail Ahmed

Assisstant Professor of Psychiatry

Ziauddin Medical University Hospital Kemari Campus

Karachi, Sindh-Pakistan.

Dr. Mohan Lal Luhano

Sir C.J. Institute of Psychiatry

Hyderabad, Sindh-Pakistan. 